\title{
Numerical and Experimental Investigation of a Wall Jet
}

\author{
Gamal H. Moustafa and Mousa M. Mohamed \\ Dept. of Power Mechanical Engineering, Faculty of Engineering, \\ Menoufia University, Shebin El-Kom, \\ Egypt.
}

\begin{abstract}
Numerical and experimental investigations for a wall jet at different conditions were carried out in order to understand the behavior of such a jet. A low speed incompressible jet was produced by a circular nozzle with the range of the mean velocity at the nozzle exit plane from 40 to $120 \mathrm{~m} / \mathrm{s}$. Measurements of the static and total pressures were made at different planes normal to the nozzle axis in the downstream direction. A finite difference solution for the hydrodynamic and thermal boundary layer formed by the wall jet over an isothermal plate at varying values of the initial Reynolds number was presented. The solution was obtained by a marching technique suitable for parabolic differential equations. At the first, the solution procedure was applied on the free jet and then reformulated to the wall jet. Experimental and numerical results are in good agreement with the previous work. The oil film visualization gives details of the spreading and decay processes of the jet.
\end{abstract}

Keyword: Wall Jet, Free jet, Spreading rate, Decay rate, Coanda effect, oil film.

Manuscript received from $\mathrm{Dr}$. Gamal $\mathrm{H}$. Moustafa

Accepted on : $23 / 6 / 2001$

Engineering Research Journal Vol 24,No 3, 2001 Minufiya University, Faculty Of Engineering , Shebien El-Kom , Egypt , ISSN 1110-1180 


\section{Introduction}

The study of jet boundary interaction problems include impinging, wall, and offset jets is useful for developing different types of engineering devices. In the impinging jet, the fluid stream is directed toward a surface. In the wall jet, it is discharged parallel to and along a surface. In the offset jet, the fluid is discharged parallel to a surface from a nearby outlet. Clearly, the wall jet is a limiting case of the offset jet. Therefore, a plan wall jet is a flow configuration obtained by injecting fluid along a wall at a velocity higher than that in the ambient flow. It has features of a boundary layer and a free shear layer. Main applications are turbine blade cooling and airfoils in high lift configurations. In the former case it is desirable to prevent the cooling fluid from mixing with the ambient flow in order to sustain the protective layer as far downstream as possible. In the latter case, the simulation of mixing of the wall jet with the ambient flow is desirable in order to supply momentum to a boundary threatened, for example, by separation.

A wall jet also exists in many engineering applications such as in the natural environment (rivers and canals) and in man made devices (heat and mass transfer operations). In fact, the flow field of the wall jet could be divided into three flow regions. Figure 1 shows the re-circulated, impingement and wall jet regions. The presence of a boundary in the vicinity of a jet has a significant effect on the jet's behavior. The most obvious effect is the deflection of the jet towards the wall and eventual impingement on the surface. The existence of an open gap between the jet and the wall allows secondary fluid to be entrained between the wall and the jet, which causes secondary fluid effects on the mean behavior. This type of flow is termed as a ventilated wall jet. This type of jet exists in many aerodynamic applications such as in powered high lift devices for STOL aircraft. Also, upper surface blowing (USB), thrust augmentor arrangements and some configurations of blown flaps consist of jet sheets blowing over adjacent surfaces and exhibiting Coanda-like "attachment" to these walls.

Many investigators have identified the main characteristics of a wall jet. Lawrence (1964) studied a cylindrical wall jet. In fact, it has pointed out that one of the methods of effectively diluting industrial effluents in a stream is to inject the former as a counter jet into the stream. Robillard and Ramamurthy (1974) explained that the presence of the wall in the rear of the jet acts like a splitter plate and inhibits the formation of an alternate vortex shedding mechanism which is normally present in the case of centrally mounted two-dimensional free counter jets. Marsters et al. (1980) provided an experimental study of the heat transfer characteristics of a ventilated jet attaching to a wall. Sharama (1981) made an experimental study on a conical wall jet and showed that the velocity profile and the rate of the jet spread follow patterns similar to those of radial, plane or cylindrical wall jets. The influence of suction on the developing wall flow of an impinging jet was studied by Obot et al. (1983). They indicate that suction creates a layer volume of flow toward the impingement surface, reduces the momentum boundary layer thickness and the wall jet to the half width, and increases velocity gradient near the surface and hence the wall shear stress. Pelfrey and Liburdy (1984) provided a detail study of the mean and turbulent flow characteristics of a wall jet. Tsitouras and Jiji (1986) examined the three-dimensional turbulent offset 
jets discharged from rectangular channels parallel to a plane surface. They reported that the presence of a boundary in the vicinity of a jet has a significant effect on the jet's behavior. The behavior of a wall jet in laminar to turbulent regimes was also studied by Mele et. al. (1986). Rew and Park (1988) studied the interaction of two opposing, asymmetric curved wall jets. They found that the growth rate of the merged jet was approximately 1.5 times larger than that of the plane jet. Gregory-smith and Hawkins (1991) studied the development of an axisymmetric curved turbulent wall jet. Park and Rew studied the twodimensional flow generated by the interaction of two opposing, symmetric curved wall jets. They found that the overall flow field could be divided into the curved wall jet (jet region), the interaction region, and the merged jet region. The characteristics of counter flowing wall jets were also provided by Balachandar et.al. (1992). Coherent structure in three-dimensional wall jet and its effect on the mean jet behavior was studied by Matsude et. al. (1990). They suggested that the structure in the near field have a shape similar to the horseshoe vortex, which is inclined to the streamwise direction.

Recently, a new method for the control of the mixing of a plane turbulent wall jet has been investigated by Schober et al, (1999). They found that a thin wire, mounted in the vicinity of the wall jet nozzle, changes the formation of the shear layer structures in the early stages of the development of the wall jet. The wire is operated in two ways: (1) a still wire inhibits the natural shear roll-up and reduces the size of the turbulent structures and thereby the mixing: (2) a self-excited oscillating wire introduces large coherent structures and thereby enhances the mixing. The size of these structures does not depend on the shear layer instability but rather on the wire frequency.

The purpose of the present study is to obtain data for a wall jet flow at different parameters, such as spread rate, velocity and temperature profiles. Experimental work is done and the results are compared with that obtained from a numerical study. The finite difference solution with marching technique for the hydrodynamic and thermal boundary layer formed by the jet is presented. A comparison between the free jet behavior and that of the wall jet is provided. The flow pattern is visualized using an oil film technique.

\section{Experimental set up and procedure}

A schematic diagram of the experimental set-up and test section is given in Fig.2. An open circuit below down wind tunnel was used to produce the air jet. Hence, two air compressors ( $37 \mathrm{~kW}$ and $5.25 \mathrm{~m}^{3} / \mathrm{min}$, each) were used to supply air, which was similar in an air tank at a pressure of 8 bar. The air before restored was passed through an air dryer and oil separator. Then, the air was passed through a 3 inches diameter pipeline to a settling chamber. The pipeline control section includes a gate valve followed by a pressure-regulating valve. Two mesh wire screens were fixed in the settling chamber to reduce air disturbances and make the flow uniform before discharged through the nozzle into the atmosphere. A circular nozzle was fabricated from aluminum and was polished to make its surfaces as smooth as possible. The inlet and exit diameters of the nozzle were 22 and $10 \mathrm{~mm}$ and the nozzle length was $25 \mathrm{~mm}$. The jet was issued parallel to a flat 
plate, which was placed at the lower edge of the nozzle. The length of the flat plate was $800 \mathrm{~mm}$ while the width was $300 \mathrm{~mm}$. The flat plate was made of Perspex with a thickness of $10 \mathrm{~mm}$. The distance between the nozzle axis and plate was varied from 5 to $120 \mathrm{~mm}$.

Measurements of total and static pressures were made for different initial flow conditions. Pressure taps were made on the surface of the flat plate along the plate length and plate width. A Pitot tube probe of $0.5 \mathrm{~mm}$ inner diameter and outer diameter of $1 \mathrm{~mm}$ was used to measure the total pressure. The probe was fixed on a 3 dimensional traverse system with a pitch of $1 \mathrm{~mm}$ in all directions. Experiments were made, at different values of the initial flow velocity of the jet. Water and mercury U-tube manometers were connected to the pressure taps and pitot tube probe for pressure reading which was uniform to within $\pm 0.2 \%$. The uncertainly in the probe measuring location was $\pm 0.15 \%$. The stagnation pressure at the nozzle inlet was measured using a digital manometer, which was varied to give a range of an initial velocity from 40 to $120 \mathrm{~m} / \mathrm{sec}$ with uncertainty of $\pm 0.1 \%$. Hence, the Reynolds number based on the nozzle exit diameter and flow velocity at the nozzle exit was varied from $2.1 \times 10^{4}$ to $4.2 \times 10^{4}$. The nearest building walls were kept sufficiently far from the tunnel to exclude their effects. The stagnation temperature was measured using a digital thermometer whereas; a mercury thermometer was used to measure the ambient temperature. The temperature reading was uniform to within $\pm 0.3 \%$. The ambient temperature at the time of experiments was $25{ }^{\circ} \mathrm{C}$. The ambient atmospheric pressure was measured using a barometer with an uncertainty of $\pm 0.2 \%$. An oil film technique was used to visualize the flow pattern to detect the spreading and decay processes of the wall jet.

\section{Theoretical analysis}

For an incompressible, steady, axisymmetrtic laminar jet flow with constant properties, the governing equations are written as follows:

\section{Continuity Equation:}

$\frac{\partial u}{\partial x}+\frac{1}{r} \frac{\partial(r v)}{\partial r}=0$

\section{Momentum Equation:}

$$
\rho\left(u \frac{\partial u}{\partial x}+v \frac{\partial u}{\partial r}\right)=\mu \frac{1}{r} \frac{\partial}{\partial r}\left(r \frac{\partial u}{\partial r}\right)
$$




\section{Energy Equation:}

$$
\rho C_{p}\left(u \frac{\partial t}{\partial x}+v \frac{\partial t}{\partial r}\right)=k\left(\frac{\partial^{2} t}{\partial r^{2}}+\frac{1}{r} \frac{\partial t}{\partial r}\right)
$$

\section{Boundary conditions:}

The governing set of partial differential equations has to be solved with the following boundary conditions:

$$
\begin{array}{lll}
u(r, 0)=u_{o} & t(r, 0)=t_{o} & r \leq a \\
u(r, 0)=0 & t(r, 0)=t_{a} & r>a \\
u(\infty, x)=0 & t(\infty, x)=t_{a} & \\
\frac{\partial u}{\partial r}(0, x)=0 & \frac{\partial t}{\partial r}(0, x)=0 & \\
v(0, x)=0 & &
\end{array}
$$

The basic equations are made dimensionless as the following:

$$
\begin{array}{lll}
U=\frac{u}{u_{o}} & V=\frac{v}{u_{o}} R_{e} & T=\frac{t-t_{a}}{t_{o}-t_{a}} \\
X=\frac{x}{a}\left(R_{e}\right)^{-1} & R=\frac{r}{a} & R_{e}=\frac{\rho u_{o} a}{\mu}
\end{array}
$$

The governing equations in dimensionless form become:

$$
\begin{aligned}
& \frac{\partial U}{\partial X}+\frac{1}{R} \frac{\partial(R V)}{\partial R}=0 \\
& U \frac{\partial U}{\partial X}+V \frac{\partial U}{\partial R}=\frac{1}{R} \frac{\partial U}{\partial R}+\frac{\partial^{2} U}{\partial R^{2}} \\
& U \frac{\partial T}{\partial X}+V \frac{\partial T}{\partial R}=\frac{1}{P_{r}}\left(\frac{\partial^{2} T}{\partial R^{2}}+\frac{1}{R} \frac{\partial T}{\partial R}\right)
\end{aligned}
$$


The boundary conditions in the dimensionless form become:

$$
\begin{array}{lll}
U(R, 0)=1 & T(R, 0)=1 & R \leq 1 \\
U(R, 0)=0 & T(R, 0)=0 & R>1 \\
U(\infty, X)=0 & T(\infty, X)=0 & \\
\frac{\partial U}{\partial R}(0, X)=0 & \frac{\partial T}{\partial R}(0, X)=0 & \\
V(0, X)=0 & &
\end{array}
$$

The finite difference representations of the basic equations are written as:

$$
\begin{aligned}
& \frac{U_{j+1, k}-U_{j, k}}{\Delta X}+\frac{1}{R_{k}}\left(\frac{V_{j+1, k+1} R_{k+1}-V_{j+1, k} R_{k}}{\Delta R}\right)=0 \\
& U_{j+1, k} \frac{U_{j+1, k}-U_{j, k}}{\Delta X}+V_{j+1, k} \frac{U_{j+1, k+1}-U_{j+1, k-1}}{2 \Delta R}=\frac{1}{R_{k}} \frac{U_{j+1, k+1}-U_{j+1, k-1}}{2(\Delta R)} \\
&+\frac{U_{j+1, k+1}-2 U_{j+1, k}+U_{j+1, k-1}}{(\Delta R)^{2}} \\
& U_{j+1, k} \frac{T_{j+1, k}-T_{j, k}}{\Delta X}+V_{j+1, k} \frac{T_{j+1, k+1}-T_{j+1, k-1}}{2 \Delta R}=\frac{1}{P_{r}}\left[\frac{T_{j+1, k+1}-2 T_{j+1, k}+T_{j+1, k-1}}{(\Delta R)^{2}}\right. \\
&\left.+\frac{1}{R_{k}} \frac{T_{j+1, k+1}-T_{j+1, k-1}}{2(\Delta R)}\right]
\end{aligned}
$$

The momentum equation (11) and the energy equation (12) apply for all $\mathrm{k}>0$. For $\mathrm{k}=0$, a special form must be obtained by letting $\mathrm{R}>0$, where $\mathrm{Eq}$. (7) and (8) using the L'Hospital's rule. Then, equations (7) and (8) become:

$$
\begin{aligned}
& \left.U \frac{\partial U}{\partial X}\right|_{R=0}=\left.2 \frac{\partial^{2} U}{\partial R^{2}}\right|_{R=0} \\
& \left.U \frac{\partial T}{\partial X}\right|_{R=0}=\left.\frac{2}{P_{r}} \frac{\partial^{2} T}{\partial R^{2}}\right|_{R=0}
\end{aligned}
$$

Equations (13) and (14) may be written in the difference form as:

$$
U_{j+1,0} \frac{U_{j+1,0}-U_{j, 0}}{\Delta X}=4\left[\frac{U_{j+1,1}-U_{j+1,0}}{(\Delta R)^{2}}\right]
$$




$$
U_{j+1,0} \frac{T_{j+1,0}-T_{j, 0}}{\Delta X}=\frac{4}{P_{r}}\left[\frac{T_{j+1,1}-T_{j+1,0}}{(\Delta R)^{2}}\right]
$$

A special form of continuity is also necessary for $k=0$. This may be found by letting $R>0$ in equation (6) and putting in the finite difference form as:

$$
\frac{U_{j+1,0}-U_{j, 0}}{\Delta X}+2\left[\frac{V_{j+1,1}}{\Delta R}\right]=0
$$

Equation (11) written for $\mathrm{k}=1$ (1) $\mathrm{n}$ along with equation (15) for $\mathrm{k}=0$ now constitute $(n+1)$ equations in $(n+1)$ unknown $U_{j+1, k}{ }^{(1+1)}$ which may be rewritten in the matrix form as:

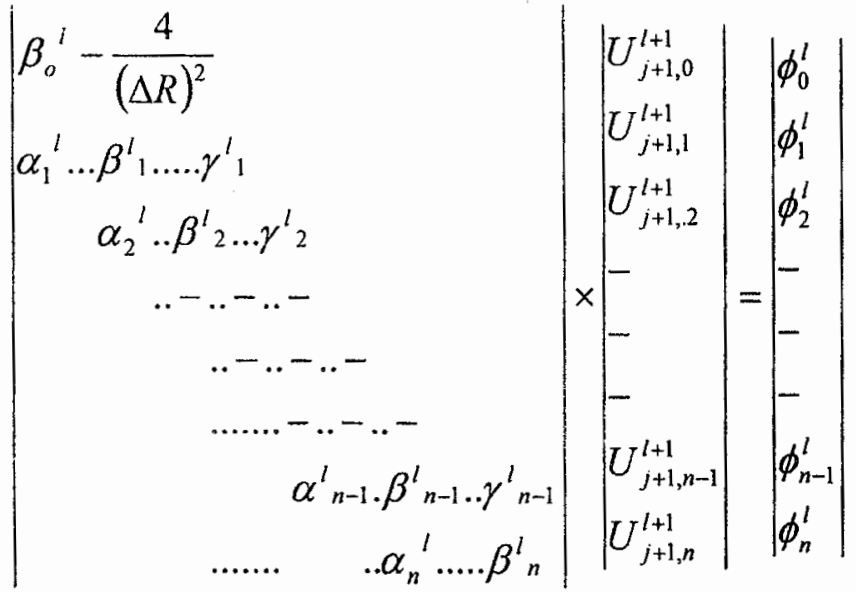

Where,

$$
\begin{array}{lll}
\alpha_{k}^{l}=\frac{-V_{j+1, k}^{l}}{2(\Delta R)}+\frac{1}{2 R_{k}(\Delta R)}-\frac{1}{(\Delta R)^{2}} & \beta_{k}^{l}=\frac{U_{j+1, k}^{l}}{\Delta X}+\frac{2}{(\Delta R)^{2}} & k>0 \\
\gamma_{k}^{l}=\frac{V_{j+1, k}^{l}}{2(\Delta R)}-\frac{1}{2 R_{k}(\Delta R)}-\frac{1}{(\Delta R)^{2}} & \phi_{k}^{l}=\frac{U_{j+1, k}^{l} U_{j, k}}{\Delta X_{4}} & \\
& \beta_{0}^{l}=\frac{U_{j+1,0}^{l}}{\Delta X}+\frac{4}{(\Delta R)^{2}} & k=0
\end{array}
$$

The superscript (1) indicates values obtained on the (1) iteration while those with superscript $(1+1)$ are the ones obtained on the $(1+1)$ iteration.

\section{Solution Procedure}

An iteration technique is applied by guessing values of $\left(U_{j+1, k}\right)^{1}$ and $\left(V_{j+1, k}\right)^{1}$ at the first iteration. Then, the tri-diagonal set of equations (18) is easy to solve, which provides $\left(U_{j+1, k}\right)^{1+1}$. The iteration process is repeated as $\left(U_{j+1, k}\right)^{l+1}$ and 
$\left(U_{j+1, k}\right)^{l}$ agree to within the desired degree of accuracy. Also, a similar requirement exists for $\left(V_{j+1, k}\right)^{1+1}$ and $\left(V_{j+1, k}\right)^{l}$. In order to complete the iteration, the values of $\left(\mathrm{V}_{\mathrm{j}+1, \mathrm{k}}\right)^{1+1}$ must be found from the continuity equation. From Eq. (17) for $\mathrm{k}=0$.

$$
V_{j+1,1}^{l+1}=\frac{\Delta R}{2 \Delta X}\left(U_{j, 0}-U_{j+1,0}^{l+1}\right) \quad k=0
$$

And from equation (10) for $\mathrm{k}>0$

$$
V_{j+1, k+1}^{l+1}=V_{j+1, k}^{l+1}\left(\frac{R_{k}}{R_{k+1}}\right)-\frac{(\Delta R) R_{k}}{(\Delta X) R_{k+1}}\left(U_{j+1, k}^{l+1}-U_{j, k}\right)
$$

The iteration is now completed and another step $\Delta \mathrm{X}$ downstream may be taken and the iterative procedure again employed. Then, the difference form of energy equation (12) for $\mathrm{k}>1$ and equation (16) for $\mathrm{k}=0$ remains linear in $\mathrm{T}$ which may be expressed in the matrix form as:

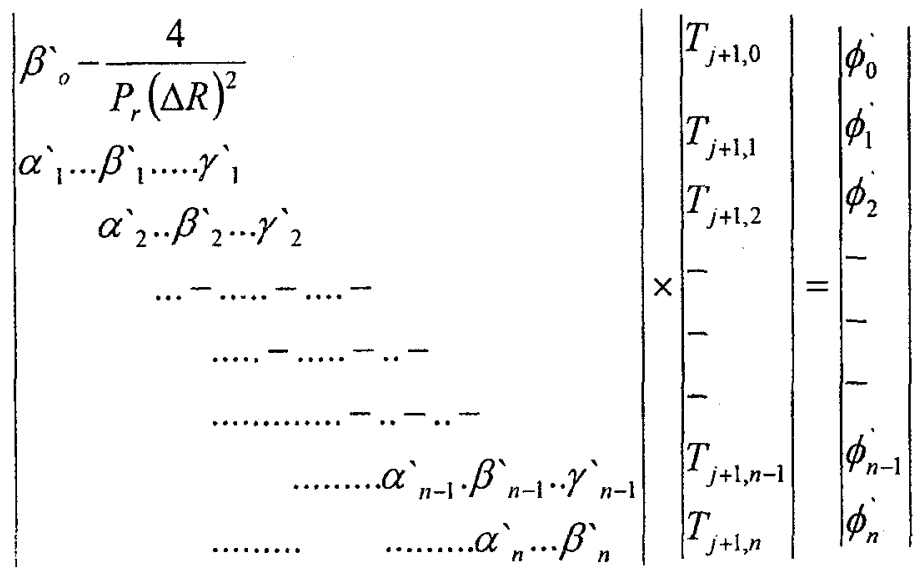

Where,

$$
\begin{aligned}
& \alpha_{k}=\frac{-V_{j+1, k}}{2(\Delta R)}-\frac{1}{P_{r}(\Delta R)^{2}}+\frac{1}{2 P_{r} R_{k}(\Delta R)} \quad \beta_{k}^{\prime}=\frac{U_{j+1, k}}{(\Delta X)}+\frac{2}{P_{r}(\Delta R)^{2}} \quad k>1 \\
& \dot{\gamma_{k}}=\frac{V_{j+1, k}}{2(\Delta R)}-\frac{1}{P_{r}(\Delta R)^{2}}-\frac{1}{2 P_{r} R_{k}(\Delta R)} \\
& \dot{\phi_{k}}=\frac{U_{j+1, k} T_{j, k}}{(\Delta X)}
\end{aligned}
$$

and 


$$
\beta_{o}^{\prime}=\frac{U_{j+1,0}}{(\Delta X)}+\frac{4}{P_{r}(\Delta R)^{2}}
$$

The truncation error of the finite difference representation at each step is of $O(\Delta \mathrm{X})$ and $O(\Delta \mathrm{R})^{2}$ for the momentum and energy equations and of $O(\Delta \mathrm{X})$ and $O(\Delta \mathrm{R})$ for the continuity equation.

\section{Boundary Conditions for the Points at the Meeting Wall}

For the case of the wall jet, the boundary conditions for the side of the jet where its boundary meets the wall are taken as follows:

$\mathrm{u}=0, \mathrm{v}=0$ and $\mathrm{t}=\mathrm{t}_{\mathrm{a}}$

\section{Results and Discussion}

Experimental results are given in the form of mean velocity decay, spreading rate and static pressure distributions along the jet centerline. A comparison between measured data and computational results are discussed.

\section{Velocity decay}

Figure 3 shows the distributions of the mean velocity of the free jet along the rdirection at various downstream locations. It is seen that the mean velocity profiles are almost uniform. The potential core ended at about $x / a=10$ and the maximum mean velocity decreases as moves from the nozzle exit plane. The position of the maximum velocity is shown at the center axis of the jet. In the far region from the nozzle exit plane, the feature of the fully developed flow is clearly dominated. The results indicate also the process of the spreading as well as the decay of the free jet. The development of the flow field of the low speed free jet shows well agreement with that of the previous study (Schlichting, 1979).

Figure 4 shows the distributions of the mean velocity of the wall jet for the offset distances $(\mathrm{H} / \mathrm{a})=5$ and 8 . In the near region, the axis of the jet (the line of the maximum velocity) tends toward the wall as the jet moves away from the nozzle exit plane in the $x$-direction. In fact, the jet attaches to the wall at a distance that depends on the distance between the nozzle and the wall (the offset distance). The attaching length is at $20<x / a<30$. It is strongly influenced by the initial values of the Reynolds number. This is because in the region between the nozzle exit plane and the attaching point, a sub-atmospheric region is existed and a reversed flow is formed near the wall. The thickness of the sub-atmospheric region increases as the offset distance is increased.

Figure 5 shows the velocity profiles in the region just downstream of the attaching point. The center axis of the wall jet (the maximum velocity line) shifts again from the wall toward the inner region of the flow field. This is due to the development of the boundary layer along the wall surface, which gives the general structure of the wall jet. In Fig. 6, the velocity profiles in the far region form the attaching point are given for the offset distance $\mathrm{H} / \mathrm{a}=8$. The velocity profiles for 
different values of $x / a$ are almost identical. Hence, the maximum value of $u / u_{0}$ is almost at the same distance from the wall. This, in fact lead to that the flow field may divide into two general regions. The inner region starts from the wall to the plane of the maximum velocity line. The outer region starts from the maximum velocity line to the plane of approximately zero velocity, which agrees well with that given in Fig.1.

A comparison of the decay of the maximum velocity for the wall and free jets is given in Fig. 7. In the near region, the decay of the wall jet is almost similar to that of the free jet. As the wall jet moves further downstream from the nozzle exit plane the decay of the maximum velocity is smaller than that of the free jet. This is because the wall prevents the entrainment of the surrounding for the case of the wall jet. The difference between them is not much due to the attachment to the wall as well as the effect of shearing stress at the wall.

The variation of the center axis of the wall jet with the downstream distance is given in Fig.8. This result shows that the center axis tends toward the wall and attaches at a certain point. The location of the attaching point changes with the offset distance as well as the Reynolds number. After the attachment, the center axis changes its direction once again away from the wall to be parallel to the wall in the far region from the attaching point, dividing the flow field into two mean regions, the outer and inner regions.

\section{Static pressure}

Figure 9 shows the variation of static pressure coefficient $\left(\xi_{p}=p-p_{a} / 0.5 p u_{0}^{2}\right)$ in the direction normal to the jet axis at various downstream locations in the $x$ direction, for the offset distance $\mathrm{H} / \mathrm{a}=1$ and 2 . For $\mathrm{H} / \mathrm{a}=1$ (there is no gap between the nozzle and the wall), the static pressure is shown above the ambient pressure. When the offset distance increases the static pressure remains almost negative in the region before the attaching point. Then, it increases to be above the atmospheric value after the attaching point. Somewhere, the static pressure becomes negative again, the negative pressure after the attaching point is in fact due to the development of the boundary layer on the wall after the attachment.

The distributions of the static pressure in the r-direction as a function of the Reynolds number are given in Fig. 10. After the jet attaches the wall the distributions of the static pressure give an idea about the wall jet flow pattern. The jet spreads in the $z$-direction and the width of the jet depends on the upstream Reynolds number. In the near region, just downstream of the attaching point the static pressure is above the ambient pressure and its maximum is again seen to be strongly influence by the initial Reynolds number. As moves far from the attaching point the static pressure decreases due to the surrounding entrainment.

Figure 11 shows the variation of the static pressure along the jet centerline, for $\mathrm{H} / \mathrm{a}=5$. It is observed that the pressure is negative near the nozzle exit. The minimum value and its position from the nozzle exit plane change with the initial value of the Reynolds number. Suddenly, the static pressure increases from the negative value to the positive value showing the maximum value at the attaching 
point. It has to note that the general features of the static pressure coefficient are similar for the various values of the Reynolds. The sudden expansion near the nozzle results in sub-atmospheric pressures that cause the jet to tend toward the surface, giving the negative values of $\mathrm{Cp}$ as shown in the Fig. 11. As the jet approaches the horizontal surface, it decelerates resulting in an increase in the pressure coefficient, becoming positive at the attaching point, where the jet impinges on the wall. The attaching length increases as the Reynolds number is increased. After the attachment the static pressure decreases to be equal to the ambient pressure in the far region.

\section{Spread rate}

The variations of upper, lower and center axis of the wall jet for $\mathrm{H} / \mathrm{a}=2$ are given in Fig. 12. These boundaries are calculated as the point where the mean velocity in the $\mathrm{r}$-direction is $0.1 \mathrm{u}_{0}$. The spreading of the upper boundary of the wall jet is approximately linear as that of the free jet with lower rating. This is due to the wall effect or what is known as the Coanda effect.

\section{Numerical Results}

Figure 13 shows the variation of the mean velocity profiles in the downstream location for the free jet calculated from the numerical code. The potential core is clearly seen in which the velocity around the jet axis remains equal to the velocity at jet axis. The jet spreads as moves from the nozzle exit plane and the fully developed flow pattern is dominated in the far region. A comparison with the results of Schlichting, (1979) and that of the experimental are given in Fig. 14. The agreement between them is well.

\section{Velocity contours}

Figure 15 shows the contours of the mean velocity of the free jet calculated from the numerical model. These contours give good idea about the structure of the free jet. The spreading of the jet and the mean velocity decay are clearly seen. The maximum velocity is at the jet center that decreases as the jet moves in the downstream.

The contours of the mean velocity for the wall jet are given in Fig. 16 for the offset distance 2 and 4 . The results identify the flow field of the wall jet. The location of the attachment point is clearly seen. The results show that the offset distance affects the attachment process and the jet spreading. As the offset distance increases the tending of the jet axis toward the wall is increased and the sub-atmospheric region is also increased. After the attachment, the threedimensional wall jet is generated, which has a similar flow pattern in the far region given the same tendency.

\section{Temperature profiles}

Figure 17 shows the distribution of the mean temperature of the free jet calculated from the numerical model. It is indicated that the mean temperature profile showed symmetry about the jet axis. Thus, the only one half is plotted here. The effect of Reynolds number on the temperature distribution in r-direction is controlled by the thermal layers development on the jet sides due to the 
surrounding entrainment. Approximately, the same thickness of the thermal layer is found for various values of the Reynolds number.

The variation of the mean temperature in the $r$-direction of the wall jet is given in Fig.18. It is seen that the mean temperature increases as the jet moves downstream and the maximum temperature is shown at the plate surface after the attachment.

The variation of the mean temperature along the center-axis of the wall jet is shown in Fig. 19. For the lower values of the offset distance $H / a=1$, the peak of the mean temperature is at the nozzle exit and decreases as moves in the downstream direction. The similar profiles are shown with varying the initial Reynolds number. For higher values of the offset distance, the peak of the mean temperature shifts slightly from the nozzle exit. This is due to the sub-atmospheric region developed just at the nozzle exit, which the surrounding entrainment.

\section{Flow visualization}

Flow visualization has been conducted using an oil film technique and exposure was done until a clear picture was obtained. Sample of these photographs was given in Fig.20, for $\mathrm{H} / \mathrm{a}=1$. The flow field is clearly seen. Shear layers at both jet sides were developed that revealing the nature of the jet flow. The jet proceeds downstream were its velocity decreases while its width increases. The spreading of the wall jet is almost linearly with the downstream distance.

\section{Conclusions}

Experimental and numerical studies have been carried out of the low speed wall jet. Measurements were made for the Reynolds number ranging from $2.1 \mathrm{x}$ $10^{4}$ to $4.2 \times 10^{4}$. The behavior of the wall jet was compared to that of the free jet. A finite difference with marching technique was applied to find out the structure of the free as well as the wall jets at different parameters. The results are summarized as follows:

1- The structure of the wall jet is affected by the initial conditions of the flow and the offset distance.

2- As the offset distance increases the thickness of the sub-atmospheric region is increased.

3- The jet parallel to the wall attaches to the wall at a distance that depends on the initial flow velocity and the offset distance, and then it generates a wall jet has a similar velocity profiles in the far region.

4- In the far region from the attaching point, the jet proceeds parallel to the wall and the maximum velocity line divides the flow field into two mean regions. In this situation, the velocity profiles are similar for tested parameters.

5- The decay of the maximum velocity of the jet parallel to the wall is slightly less than that of the free jet, in the far region. This is due to the wall effect or what is known as the Coanda effect. Due to that, the spreading of the jet parallel to the wall is less than that of the free jet.

6- The structure of the free jet is estimated well by the present numerical model, which was re-developed to find out the characteristics of the jet parallel to the 
wall. Thus, the numerical results agree well with those of the experimental and other results (Schlichting, 1970). Flow visualization is clearly detected the flow pattern of the wall jet.

\section{References}

1- Balachandar, R., Robillard, L., and Ramamurthy, A.S., "Some Characteristics of Counter Flowing wall Jet" ASME J. of Fluid Engineering, vol.114, pp. 554$558,1992$.

2- Gregory-Smith, D.G., and Gawkins, M.J., "The Development of Axisymmetric Curved Turbulent Wall jet," Int. J. Heat and Fluid Flow, vol. 12, No. 4, pp.323$330,1991$.

3- Hornbeck, R.W., "Numerical marching techniques for fluid flows with heat transfer," Sp-297 NASA, 1973.

4- Lawrence, R.L., "Velocity Profiles from Compressible Wall jets," AIAA Journal, vol. 2, pp. 574-579, 1964.

5- Mele, P., Morganti, M., Sciblia, M.F., and Lasek, A., "Behavior of Wall jet in Laminar to Turbulent Transition, "AIAA Journal, vol. 24, pp. 938-939, 1986.

6- Marsters, G.F., Howkins, B., and Kortschak, E.K., Heat Transfer to a plane wall from a heated ventilated plane jet, Int. J. of Heat Mass Transfer, vol. 23, pp. 301-309, 1980.

7- Matsuda, H., Sei-ichi lida, and Hayakawa, M., "Coherent Structures in a Three Dimensional Wall jet, "ASME J. of Fluid Engineering, vol. 112, pp. 462-467, 1990.

8- Obot, N.T., Douglas, W.JM., and Mujumdar, A.S., Influence of suction on the developing wall flow of an impinging jet, AIAA Journal, vol. 21, No. 12, pp. 1774-1776, 1983.

9- Park, S.O., and Rew, H.S., Turbulence measurements in a merged jet from two opposing curved wall jets, Experiments in Fluids, vol. 10, pp. 241-250, 1991.

10- Pelfrey, J.R.R., and Liburdy, J.A., "Mean Flow Characteristics of a Turbulent Offest Jet, "J. of Fluid Engineering, vol. 108, pp. 82-88, 1986.

11- Rew, H.S., and Park, S.O., "The Interaction of Two Opposing Asymmetric Curved Wall jets," Experiments in Fluids, vol. 6, pp. 243-252, 1988.

12- Robillard, L., and Ramamurthy, A.S., Experimental investigation of the vortex street generated by a plane jet in counter flow, ASME Journal of Fluids Eng., vol. 3, pp. 43-48, 1974.

13- Schlichting, H., "Boundary layer theory," 7 th. ed., McGraw - Hill, 1979.

14- Schober, M., Grewe, F., and Fernholz, H.H., Turbulence control in wall jets; A Visualization study, Int. J. of Fluid Dynamics, vol. 3, No. 1, 1999.

15- Sharma, R.N., "Experimental Investigation of Conical Wall Jets," AIAA Journal, vol. 19, pp. 28-33, No.1, 1981.

16- Trentacoste, N., and Sforza, P., "Further experimental results for three dimensional free Jets," AIAA Journal, vol. 15, No.5, pp. 885-890, 1967.

17- Tsitouras, C.D., and Jiji, L.M., Experimental study of surface pressure in three dimensional turbulent jet / boundary interaction, AIAA Journal, vol. 24, No. 7, pp. 1201-1203, 1986. 


\section{Nomenclature}

a : nozzle radius

$C_{p}$ : specific heat

$\mathrm{H}$ : the offset distance

$\mathrm{K}$ : thermal conductivity

$\mathrm{p}_{\mathrm{a}}$ : ambient pressure

$p_{0}:$ stagnation pressure

$p_{s}:$ static pressure

$\mathrm{P}_{\mathrm{r}}$ : Prendtle number

$T$ : temperature

$t_{a}:$ ambient temperature

$t_{0}$ : temperature at nozzle exit $\mathrm{u} \quad$ : mean velocity

$\mathrm{u}_{\mathrm{o}} \quad$ : velocity at nozzle exit

$\mathrm{v}:$ velocity in $\mathrm{r}$-direction

$r \quad:$ the radial distance from jet axis

$x \quad$ : axial distance from nozzle exit

$\mathrm{R}_{\mathrm{e}} \quad$ : Reynolds number

$\rho$ : flow density

$\mu \quad:$ dynamic viscosity

$\xi_{\mathrm{p}} \quad:$ pressure coefficient

$\infty$ : ambient condition 

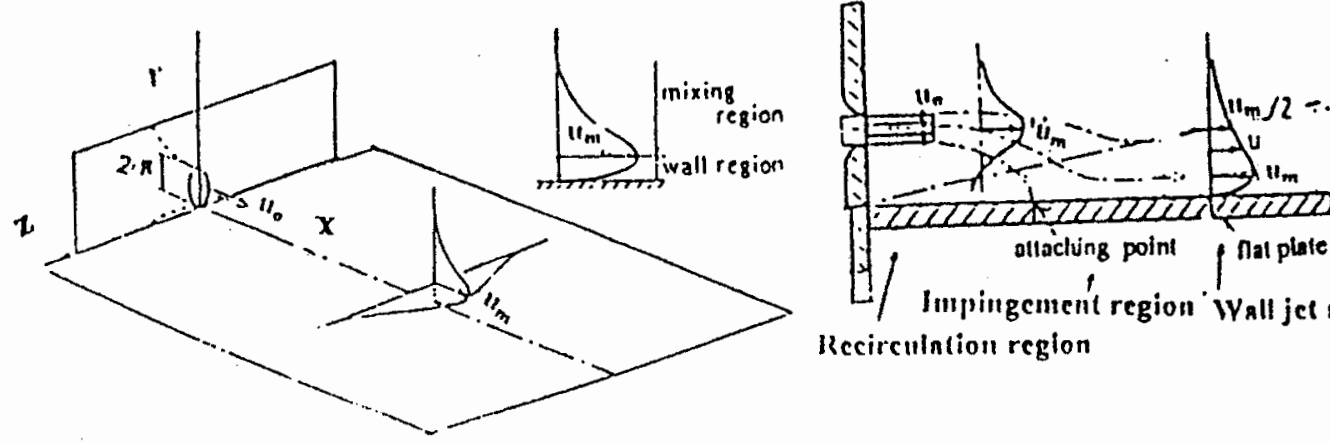

Kecirculntion region

Fig. 1 Feature of the flow field

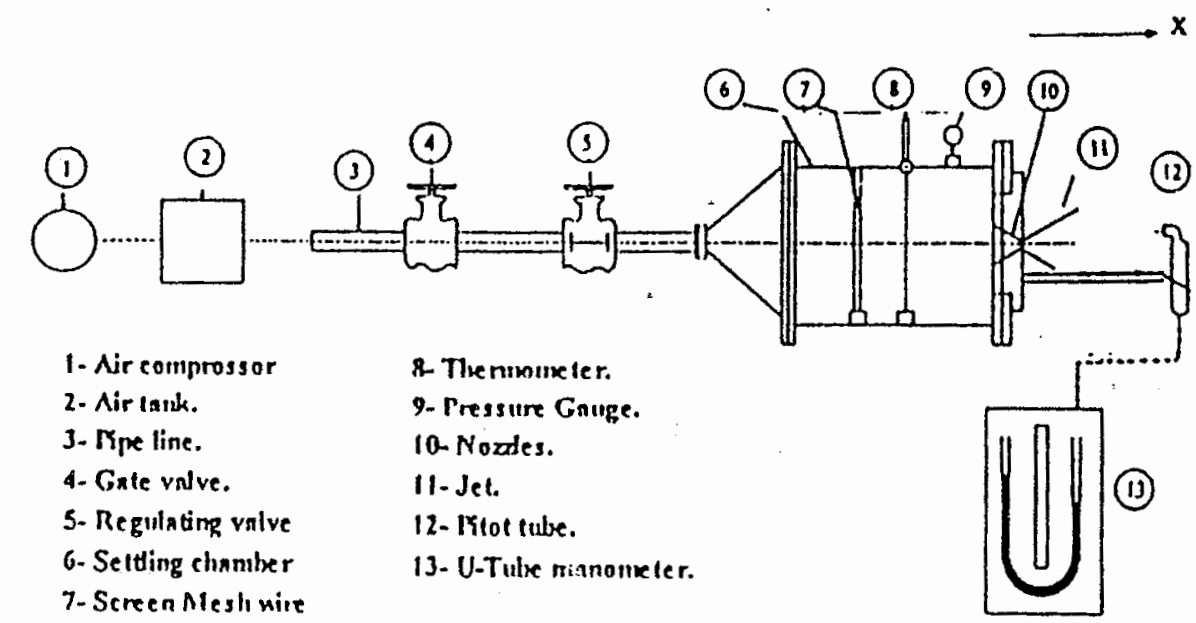

Fig. 2 Experimental set up and test section

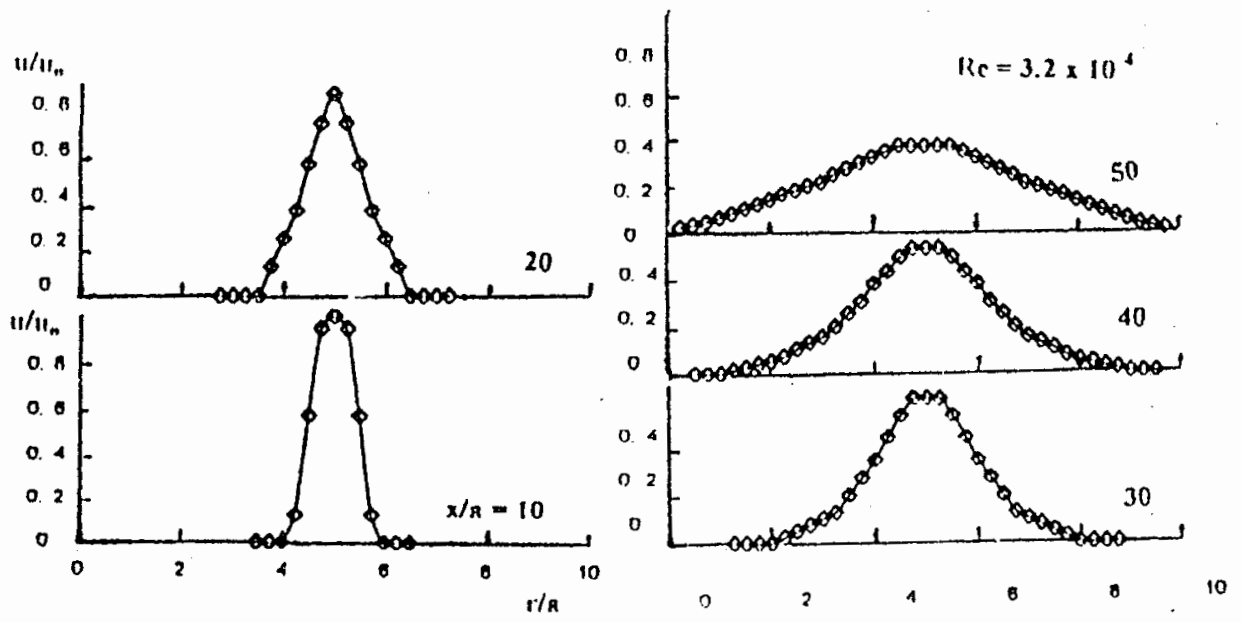

Fig. 3 Velocity profiles of a free jet 

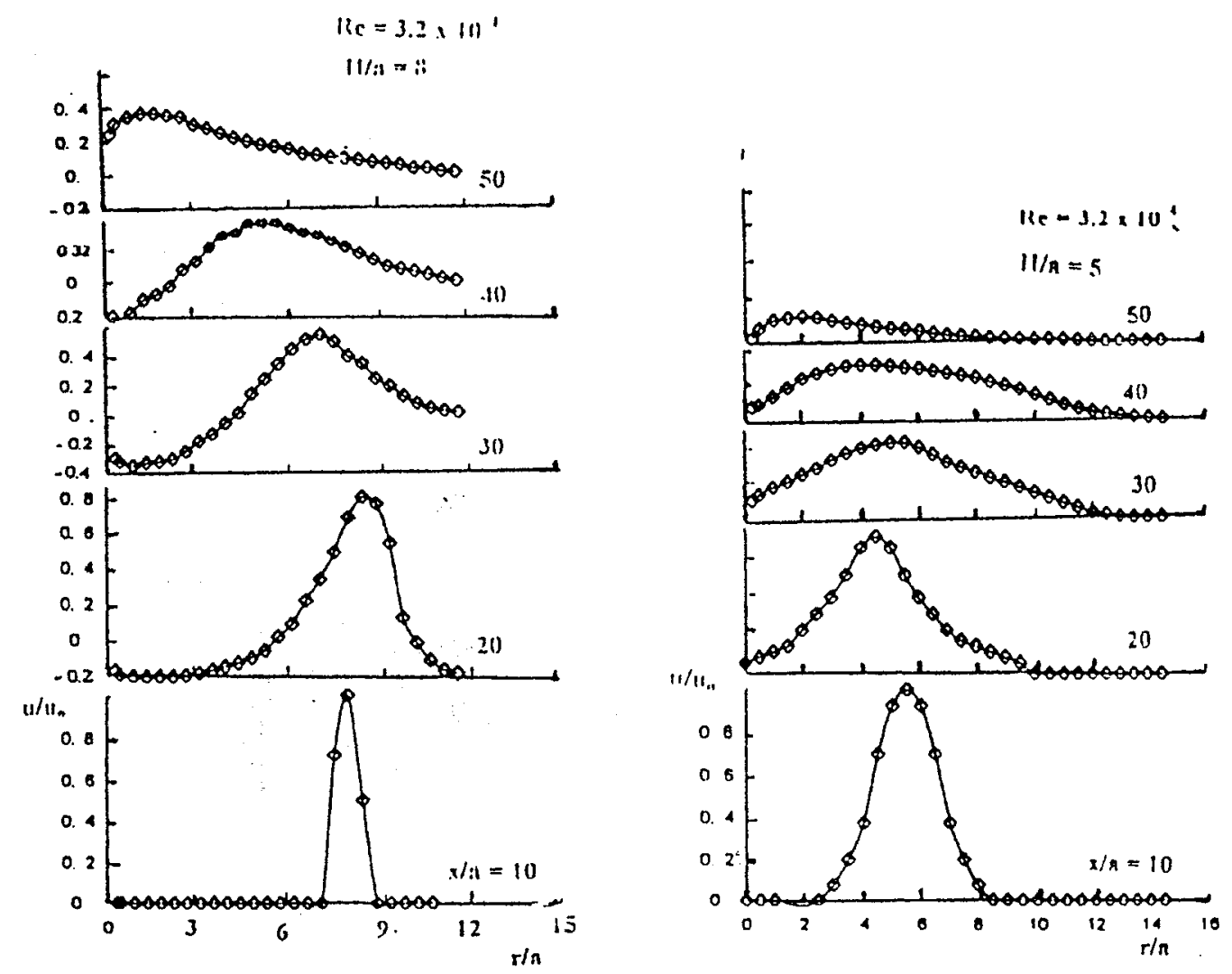

Fig. 4 Velocity profiles of a wall jet
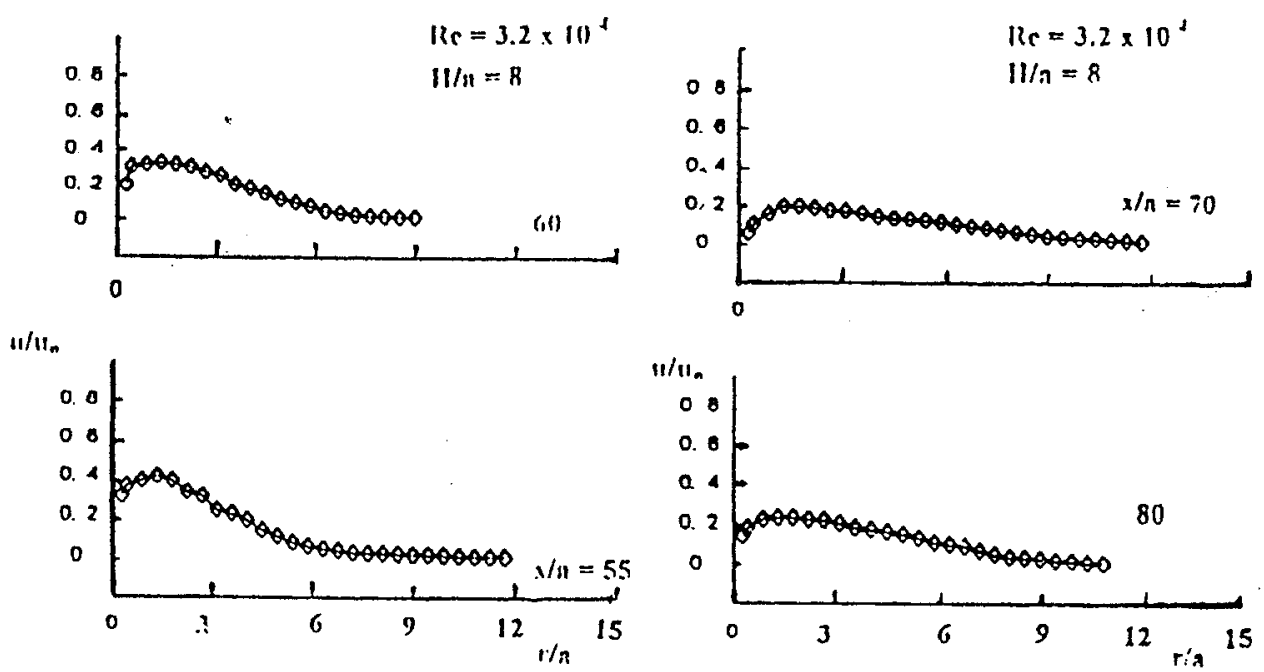

Fig. 5 Velocity profiles after the attaching point Fig. 6 Similarity profile of in the far region 


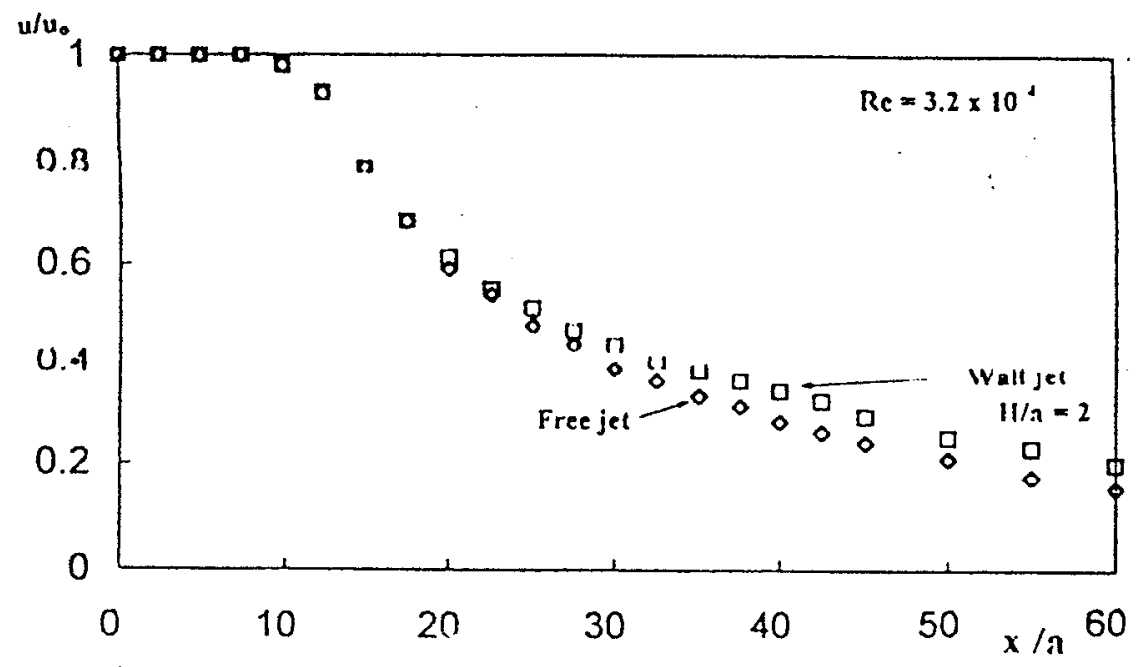

$r_{m} / a \quad$ Fig. 7 Decay of the axial mean velocity

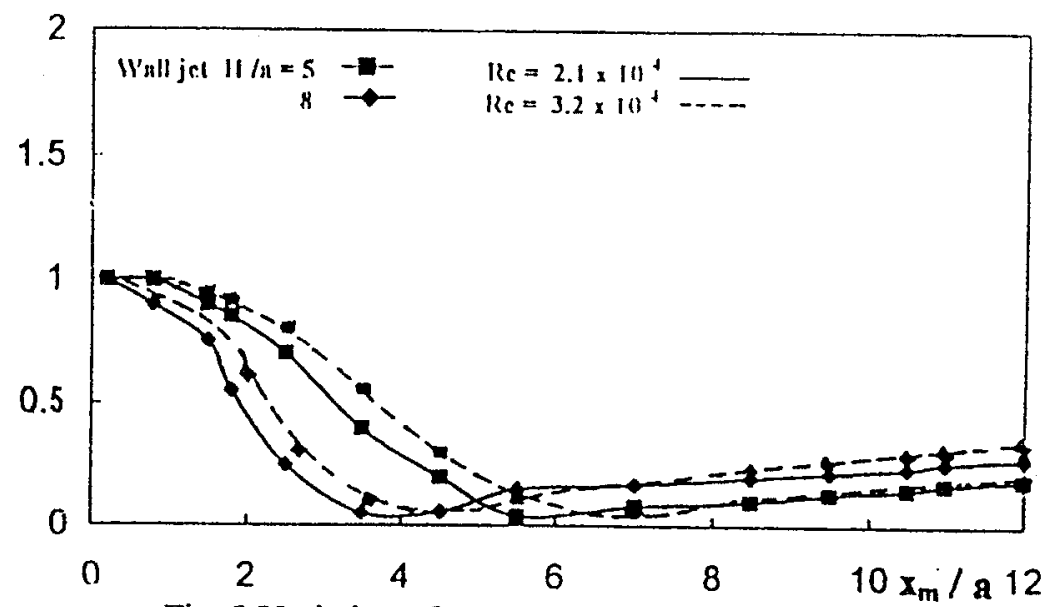

Fig. 8 Variation of center axis of a wall jet
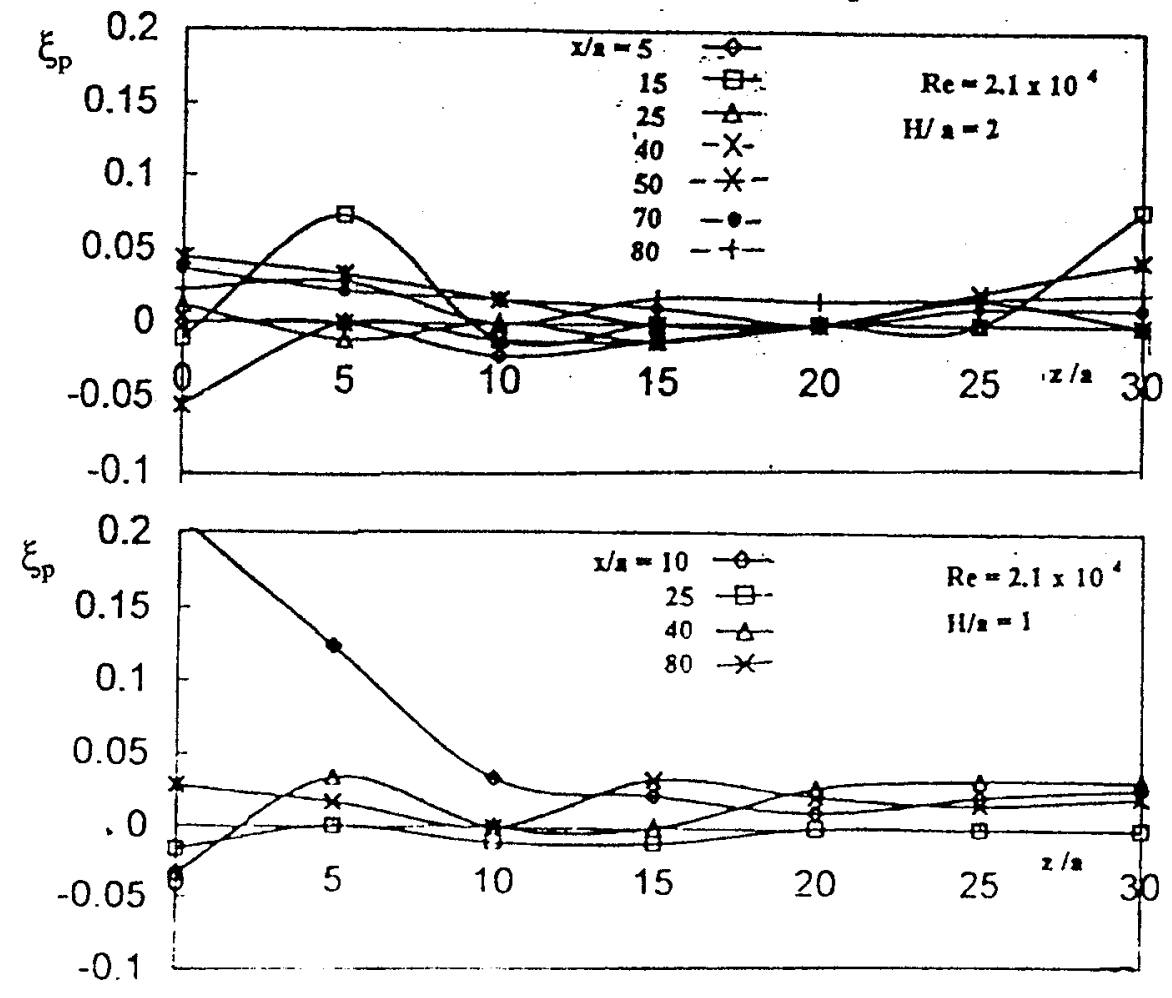

Fig. 9 Variation of static pressure coefficient with downstream distance 

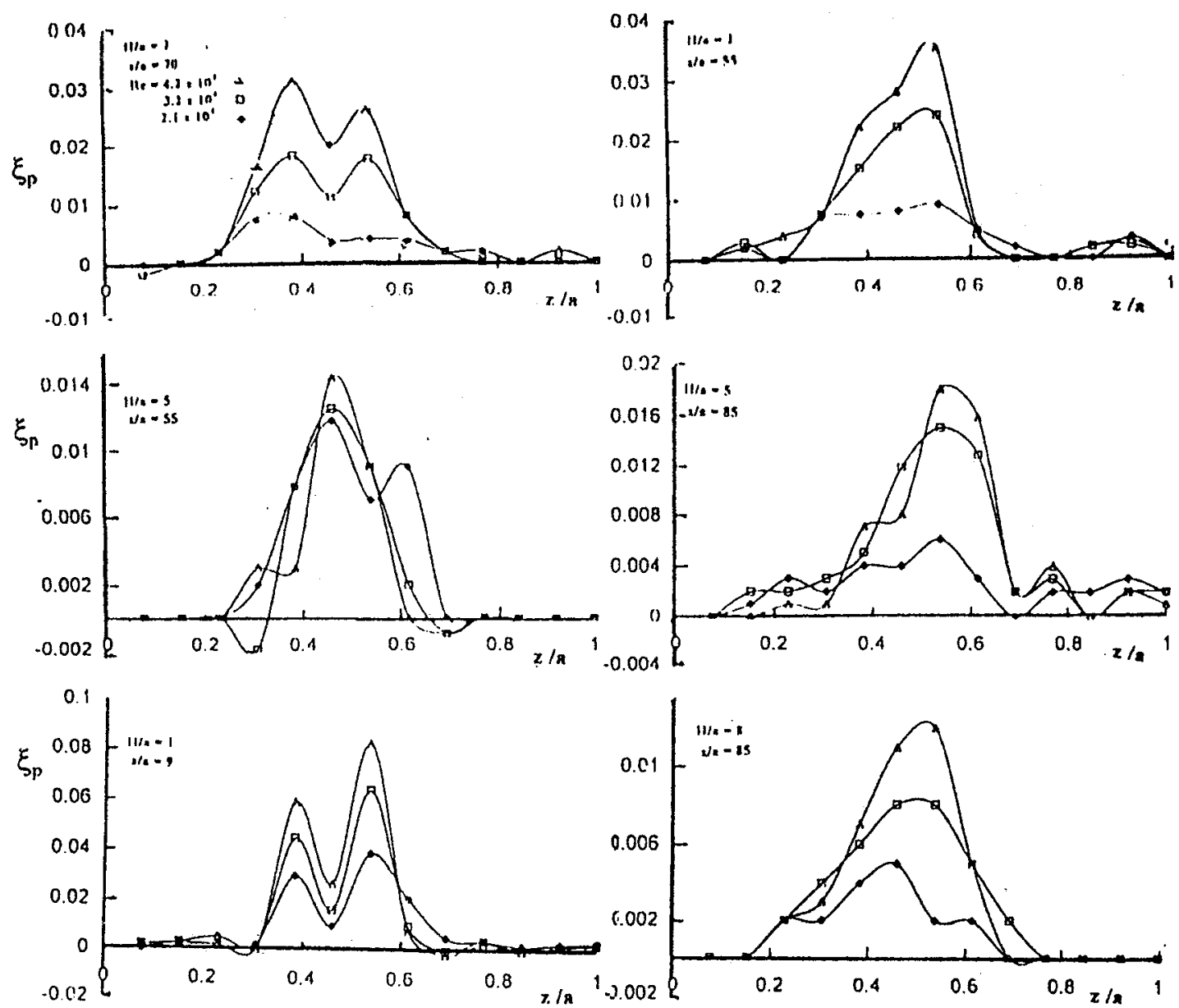

Fig. 10 Variation of static pressure in $r$-direction

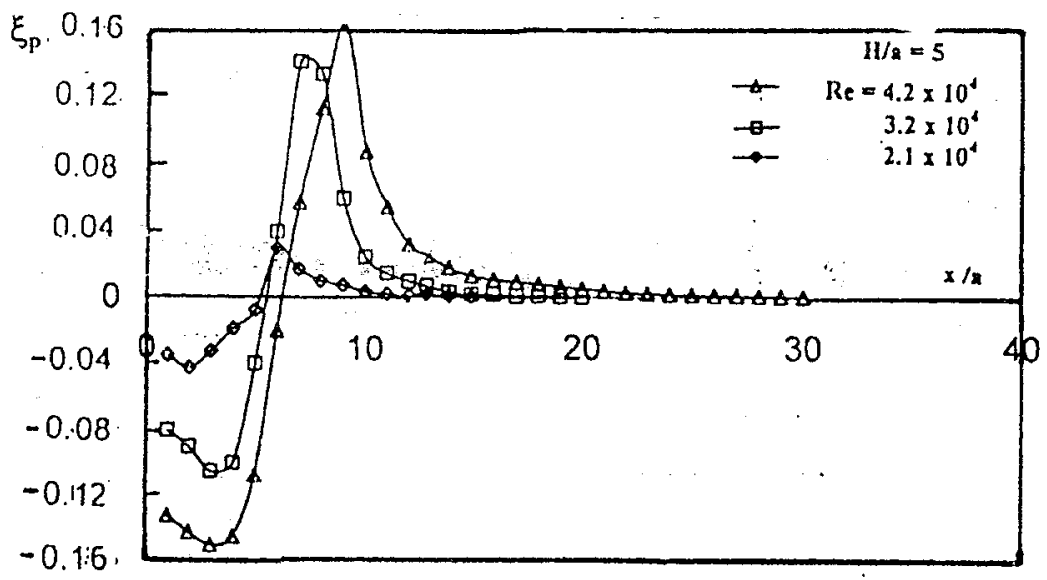

Fig. 11 Variation of static pressure along the jet axis 


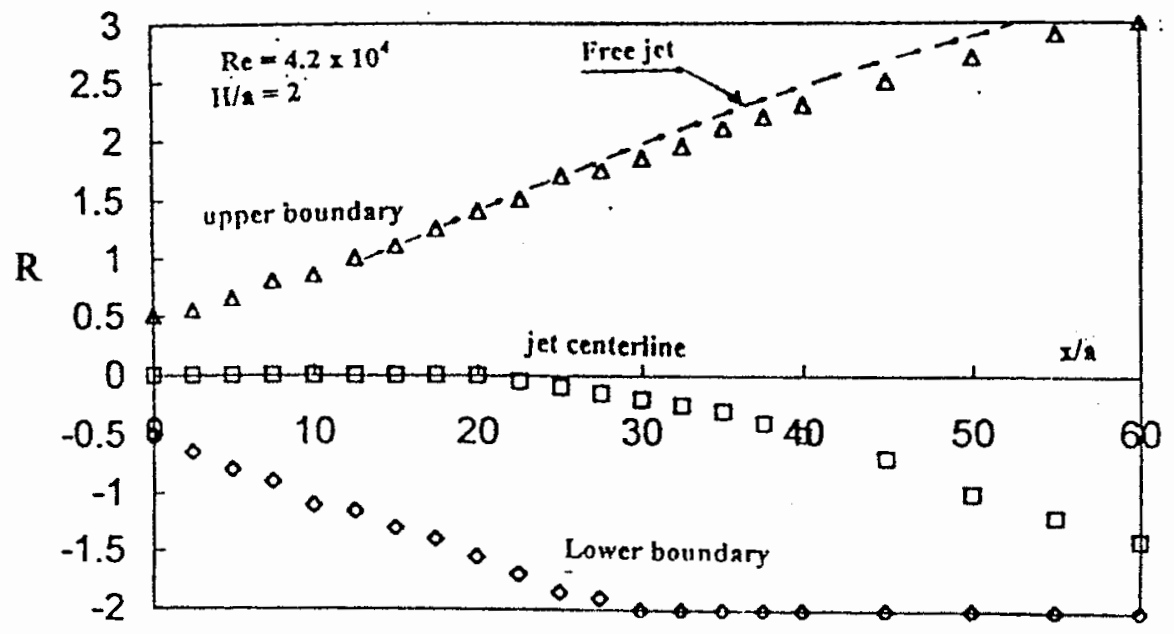

Fig.12 Spreading of a wall jet

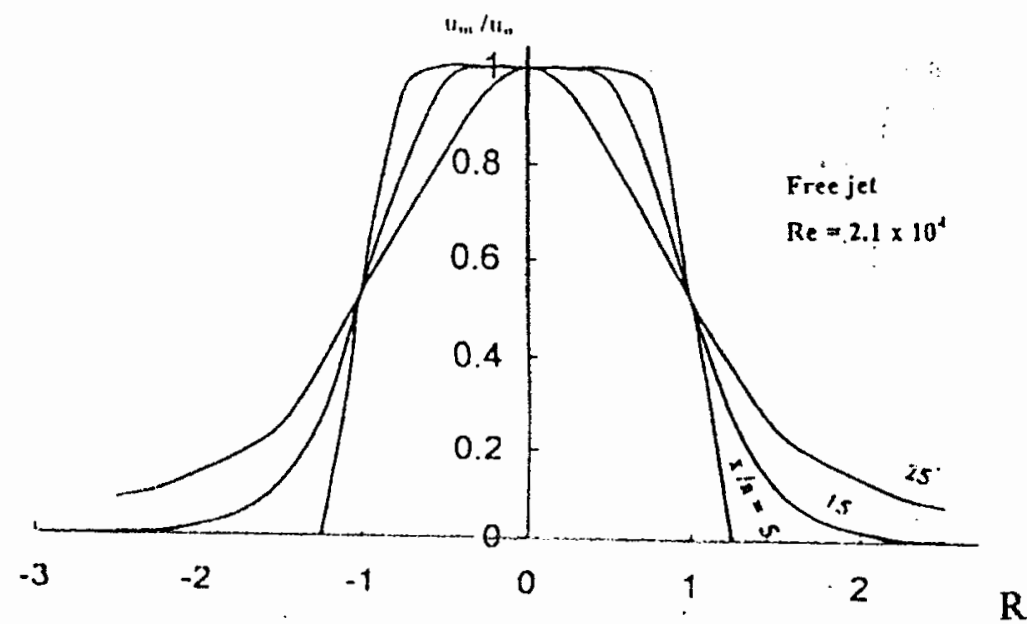

Fig.13 Velocity profiles calculated from numerical code

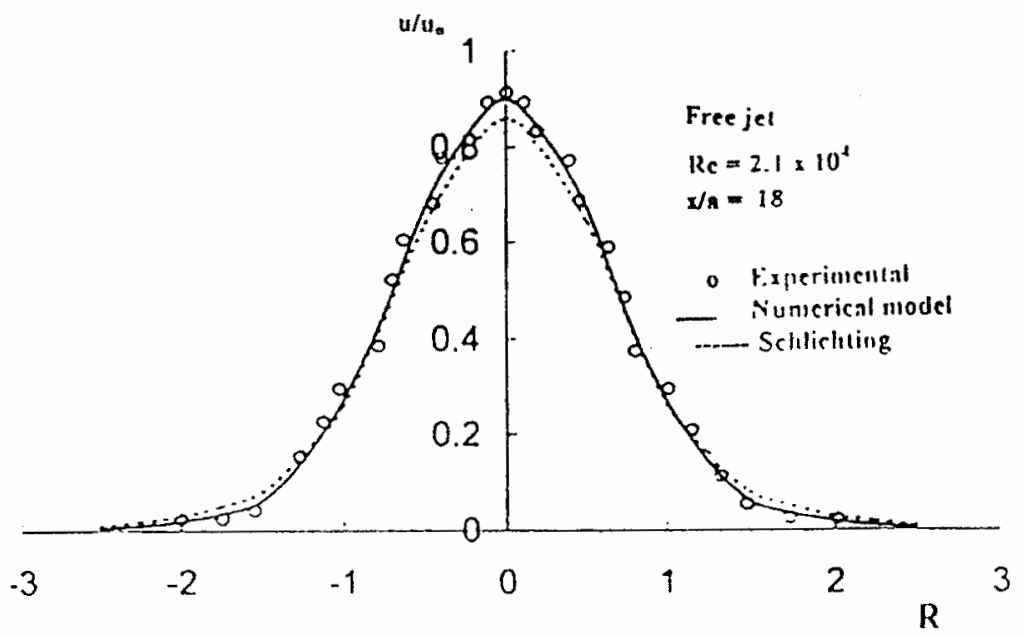

Fig. If Comparison with previous work 


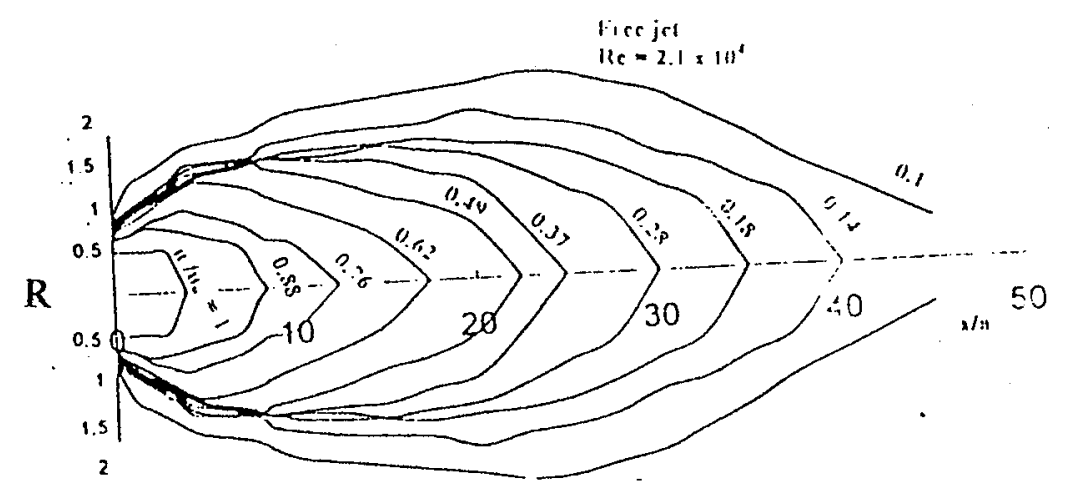

Fig. 15 Velocity contours of a free jet
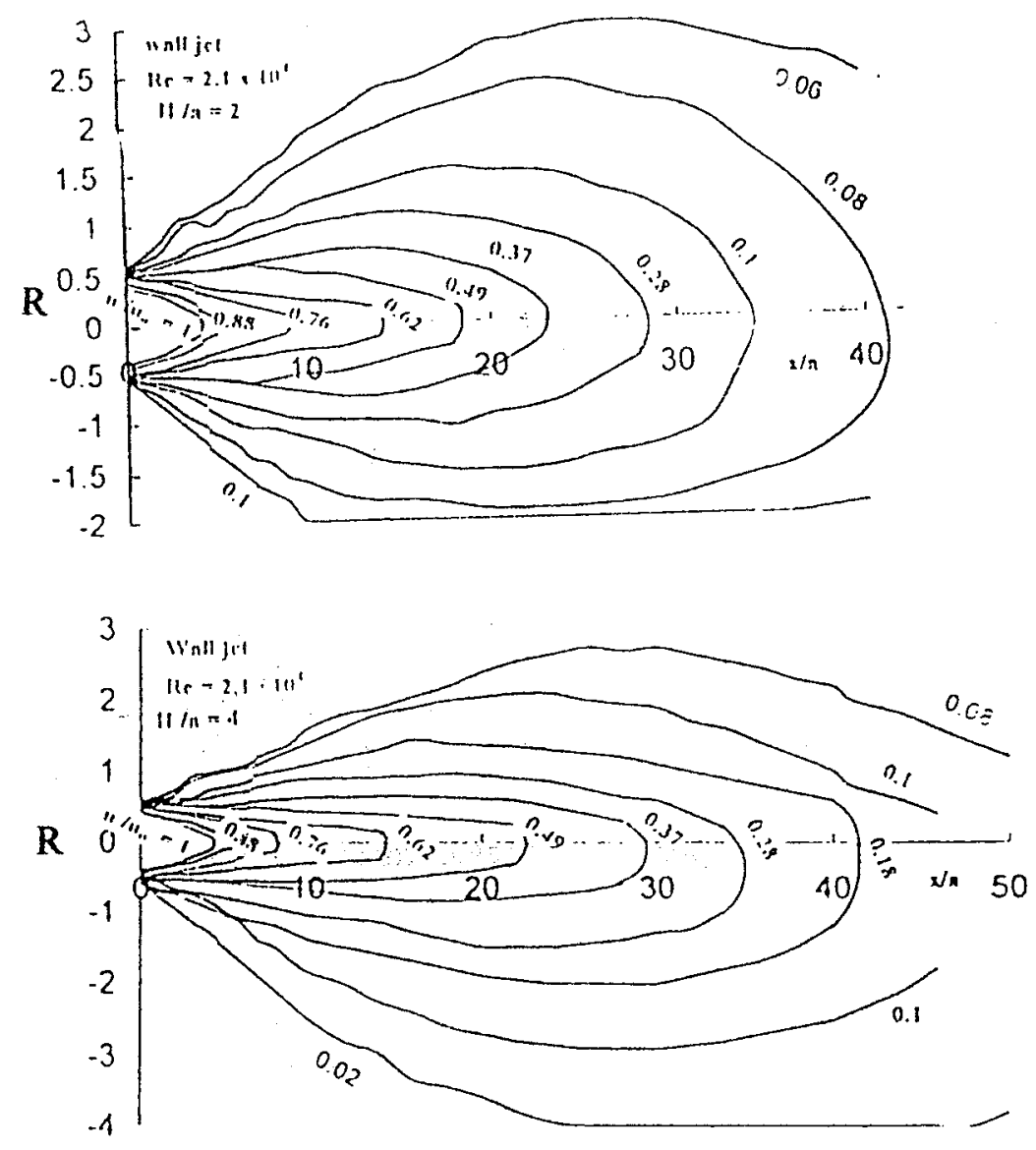

Fig. 16 Velocity contours of a wall jet 


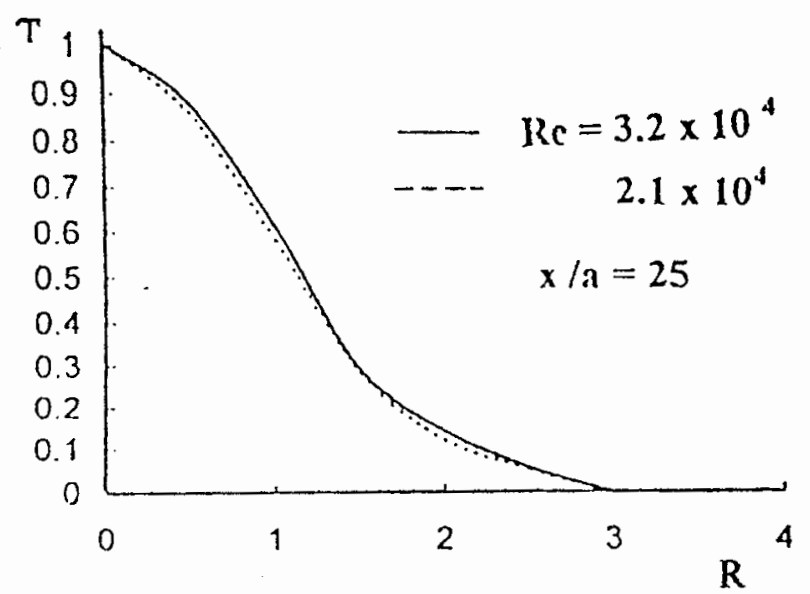

Fig.17 Distribution of mean temperature of a free jet

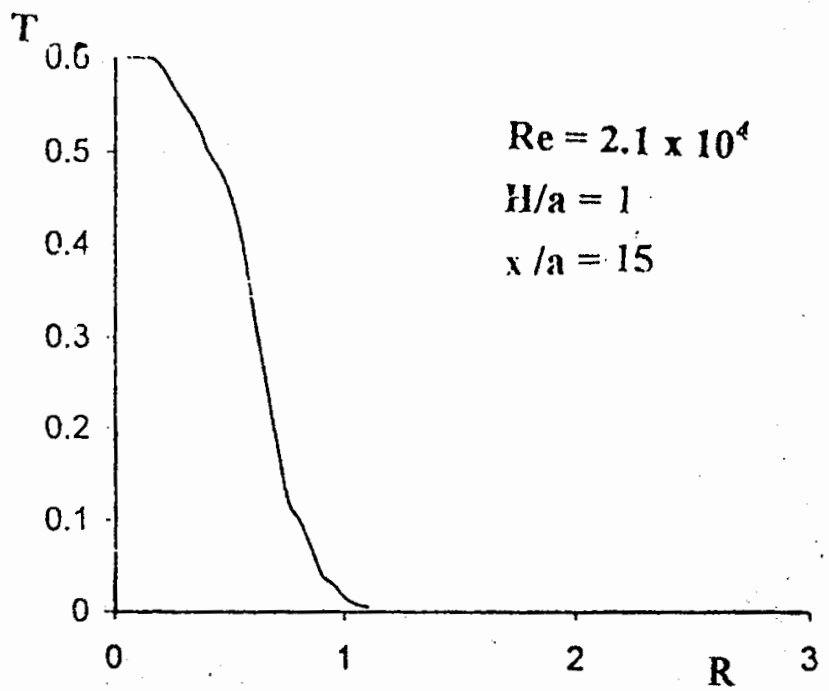

Fig.18 Variation of mean temperature in $r$-direction

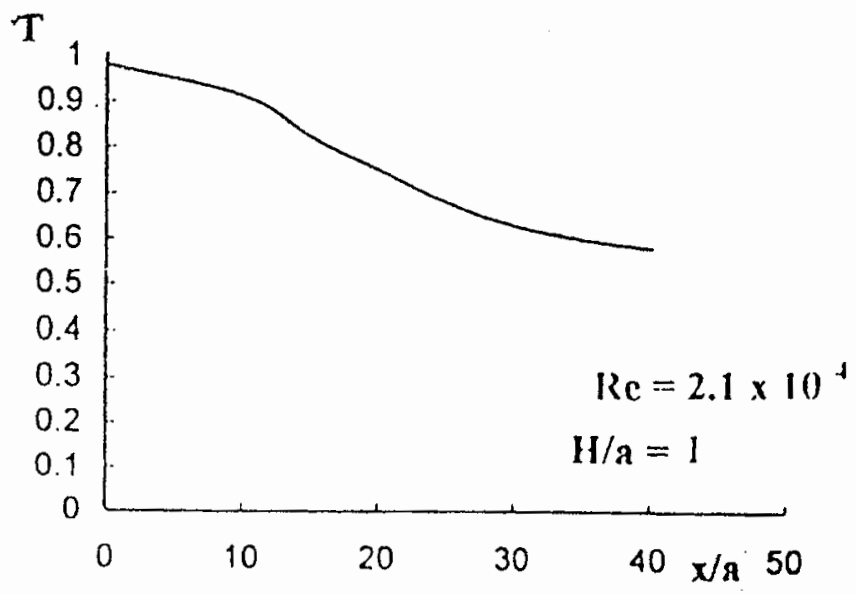

Fig. 19 Variation of mean temperature along jet asis 

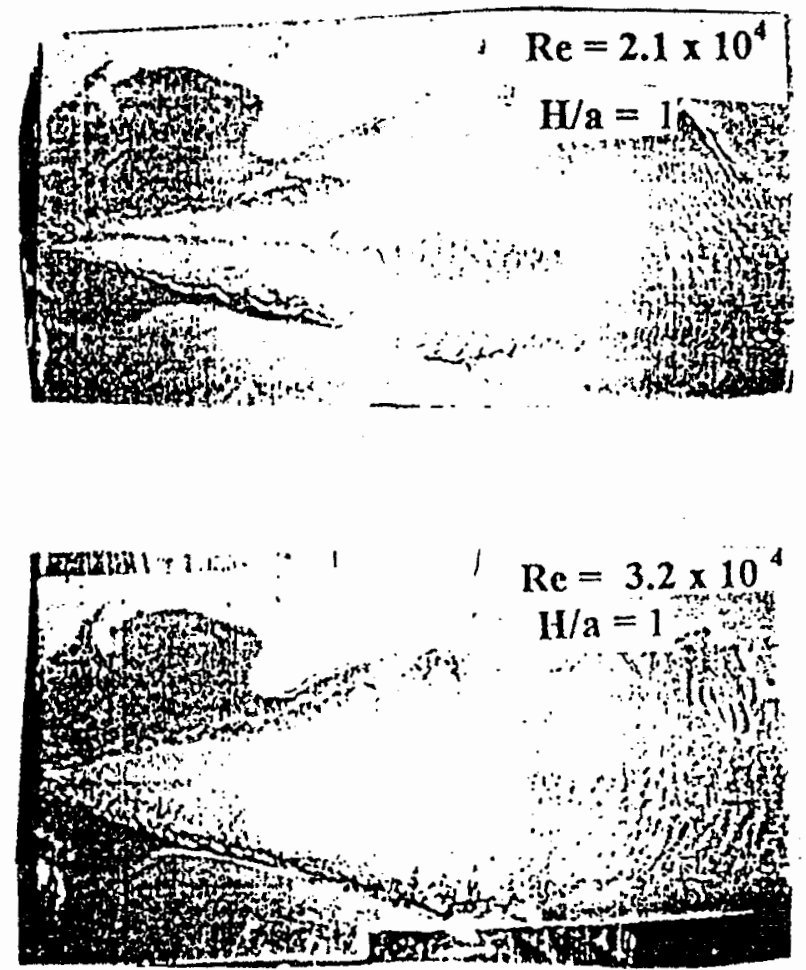

Fig. 20 Flow visualization of the wall jet 


\section{دراسة عددية وعملية لسلوك نقث موازى لجدار

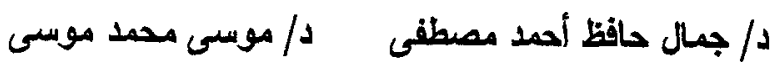

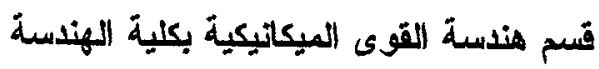 \\ جامعة المنوفية}

يتاول البحث در استة عملية ونظرية لسلوك نفث صادر من بوق دائرى موازى جدار عند

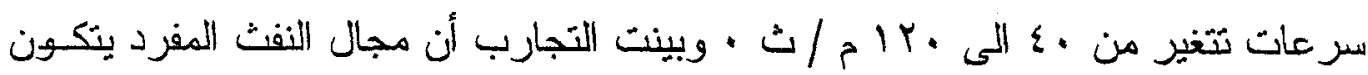
two-) ، (potential core region) من ثلاث مناطق رئيسية تحدد ملامح النفــثب وهئ

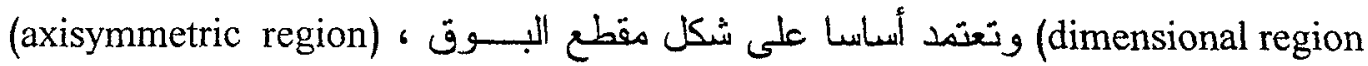

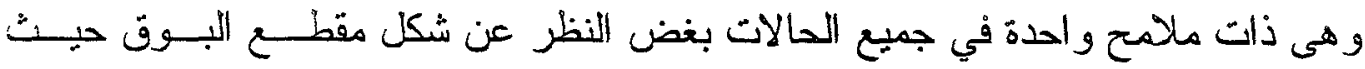
ينحول النفث المتث و البيضاوى إلى النفث الدائري في المنطقة البعيدة من مخرج البوق • وفى حالة استخدام اكثر من بوق (twin and triple jets) فقد وجد أن هناك ثلاكث منـــاطق

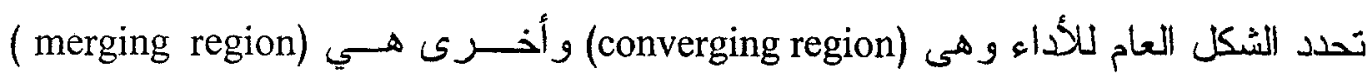

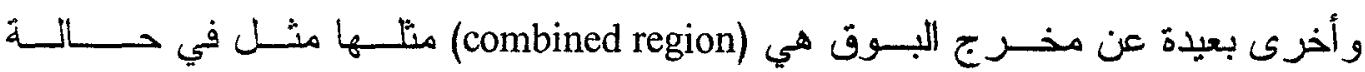

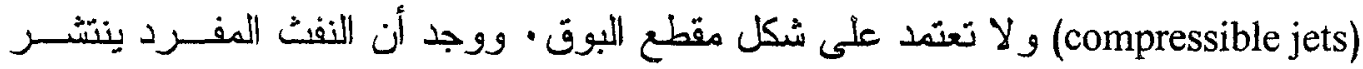

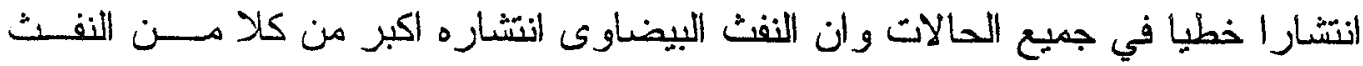

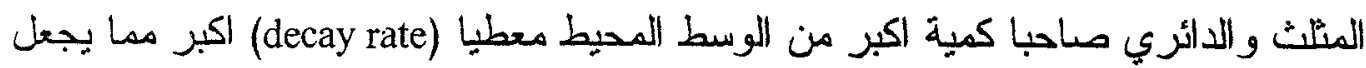

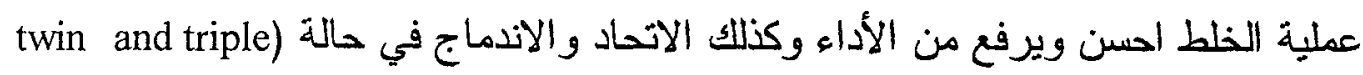
و وبينت التجارب عند تصوير مجال النفث أن هنالك اتفاق مع النتائج المقاسة. 